\title{
Burden of constipation-predominant irritable bowel syndrome (IBS-C) in France, Italy, and the United Kingdom
}

This article was published in the following Dove Press journal:

Clinical and Experimental Gastroenterology

7 November 2012

Number of times this article has been viewed

\section{Marco daCosta \\ DiBonaventura' \\ Mercedes Prior ${ }^{2}$ \\ Pablo Prieto ${ }^{2}$ \\ Josep Fortea ${ }^{2}$}

'Health Outcomes Practice, Kantar Health, New York, NY, USA; ${ }^{2}$ Global Market Access, Marketing and Medical Affairs, Almirall, Barcelona, Spain
Correspondence: Marco daCosta DiBonaventura

II Madison Avenue, 12th Floor, New York, NY I0010, USA

$\mathrm{Tel}+\mathrm{I} 2127063988$

$\mathrm{Fax}+\mathrm{I} 2126477659$

Email marco.dibonaventura@

kantarhealth.com
Background: Several studies have examined the effect of irritable bowel syndrome (IBS) on health outcomes in Western Europe, but less research has focused on the constipation subtype (IBS-C). The current study addresses this gap by comparing patients with IBS-C and matched controls for health status, work productivity, and resource utilization.

Methods: Data were obtained from the 2010 5EU National Health and Wellness Survey (NHWS), which includes respondents from France, Germany, Italy, Spain, and the UK. Only participants from France $(n=15,051)$, Italy $(n=7580)$, and the UK $(n=15,065)$ were included in the analyses. Respondents who reported a physician diagnosis of IBS and reported only constipation symptoms were compared with respondents who did not report being diagnosed with IBS using a propensity score-matching methodology (matching on sociodemographics, health behaviors, and comorbidities). Differences between patients with IBS-C and matched controls were examined on health status (Short Form Survey Instrument version 2), work productivity (Work Productivity and Activity Impairment questionnaire), and health care resource use in the past 6 months.

Results: A total of 83 (0.55\%), 109 (1.44\%), and 204 (1.35\%) respondents reported a diagnosis of IBS with only constipation symptoms in France, Italy, and the UK, respectively. Within each country, patients with IBS-C reported significantly worse health status compared with matched controls (all $P<0.05$ ) and significantly more physician visits (all $P<0.05$ ). More hospitalizations were also observed in the UK $(P<0.05)$. Among those who were employed, patients with IBS-C in France and the UK also reported significantly more presenteeism than matched controls (all $P<0.05$ ).

Conclusion: These findings highlight the pervasive influence of IBS-C on the day-to-day functioning of sufferers, their ability to be productive at work, and their influence on the wider health care system. Significant unmet needs remain, and improved management of this condition could result in significant and clinically meaningful gains in health status as well as alleviating a societal cost burden.

Keywords: Europe, health status, work productivity, health care resource use

\section{Introduction}

Irritable bowel syndrome (IBS) is a chronic and often debilitating condition with a complex etiology. Patients may experience abdominal pain and discomfort, altered bowel function, and recurrence of symptoms over an extended period of time. ${ }^{1}$ The prevalence of diagnosed IBS is estimated to be $4.8 \%$ in Western Europe (63\% of cases being female), ranging from $1.7 \%$ in Germany to $11.5 \%$ in Italy. ${ }^{2}$ Thirty-four percent of these patients self-classify themselves as constipation-predominant. ${ }^{2}$ 
Health status impairments for those with IBS have been well-documented. A recent study using a sample of German students found that those suffering from IBS consistent with Rome III criteria had significantly lower physical and mental Short Form-12 (SF-12) health survey component summary scores than patients without IBS symptoms (mean 51.9 versus 54.0, $P<0.0001$, and mean 39.6 versus 43.7, $P<0.0001$, respectively). ${ }^{3}$ Moreover, Brun-Strang et al found that patients with IBS in France scored substantially lower on the Short Form-36 (SF-36) health survey domains and component summaries compared with the general French population. ${ }^{4}$ Also utilizing the SF-36, Akehurst et al found that patients in the UK with Rome I-consistent IBS scored significantly lower on all health status domains than controls matched for age, gender, and sociodemographics. ${ }^{5}$

Aside from its effects on health status, several studies from Western Europe have documented significant additional health care resource use attributed to IBS. Seven percent of European patients with IBS were hospitalized for their condition over a period of 12 months, $40 \%$ of patients with IBS had visited their physician at least once for their symptoms in the past 3 months, and 12\% had visited their physician several times. ${ }^{2,3}$

Indirect costs through lost work productivity have also been documented. In a systematic review of data from the US and the UK for 1990-2004, mean work loss attributed to IBS ranged from 8.5 to 21.6 days per year. ${ }^{6}$ Assessing data from eight Western European countries, Hungin et al reported that patients with IBS took a mean 5.5 sick days (versus 3.1 days for non-IBS patients) and cut short a mean 10.2 days (versus 4.8 days) per year. ${ }^{2}$ Productivity loss is not limited to employment; $13.5 \%$ of students affected by IBS missed a single day, $5.4 \%$ missed a full week, and $1.5 \%$ missed more than a week of school in the previous 4 weeks. ${ }^{3}$

Despite the extensive literature describing the humanistic and economic burden of IBS in Western Europe, few studies have assessed these effects by IBS subtype. IBS symptoms vary substantially; for example, upper digestive symptoms (such as postprandial distension or early satiety) have been found to be more common among constipation-predominant (IBS-C) patients than diarrhea-predominant (IBS-D) patients. $^{7}$ These differences in symptom presentation may explain the variability in the burden observed in prior studies, but much more work is necessary. ${ }^{7-9}$ The aim of the current study was to assess the societal impairment associated with IBS-C by comparing those with and without a diagnosis of IBS-C with respect to health status, work productivity, and resource utilization.

\section{Materials and methods Data source}

Data were obtained from the 2010 5EU National Health and Wellness Survey (NHWS; Kantar Health, New York, NY), which included 57,805 respondents from France, Germany, Italy, Spain, and the UK. The NHWS is an annual, crosssectional, self-administered Internet survey completed by a sample of adults (18 years and older). Respondents of the NHWS were recruited from an Internet panel. Members of the panel joined the study by responding to opt-in emails, coregistering with panel partners, responding to e-newsletter advertisements, and responding to online banner placements. All panelists explicitly agreed to become panel members, registered through unique email addresses, and completed indepth demographic registration profiles.

This panel served as the basis for the sample of the NHWS. Members of this panel were invited through an email invitation. To ensure representativeness, emails were sent using a stratified random sampling procedure (with strata by age and gender) to ensure the final NHWS sample was identical to the demographic profile of each individual country. All subjects provided informed consent and the study protocol was approved by an institutional review board.

\section{Sample}

Consistent with Hungin et al, IBS-C prevalence rates in Germany and Spain were the lowest of the five countries. ${ }^{2}$ As a result, sample sizes were considered too small ( $\mathrm{n}=99$ and $\mathrm{n}=18$ for Germany and Spain, respectively) for sufficient country-level analysis, and only participants from France $(\mathrm{n}=15,051)$, Italy $(\mathrm{n}=7580)$, and the UK $(\mathrm{n}=15,065)$ were included in the analyses.

\section{Measures}

IBS-C

The primary independent variable for this study was a dichotomous IBS-C variable, ie, those who reported they had been diagnosed with IBS by a physician and who reported only constipation symptoms versus those who did not report being diagnosed with IBS.

\section{Sociodemographics and health history}

Several variables were considered when describing and comparing patients with IBS-C relative to patients without IBS-C. These variables included age, gender, annual household income (below the country median, above the country median, or declined to answer), body mass index (underweight, normal weight, overweight, obese, or declined 
to answer), alcohol use (those who drink versus those who do not), smoking status (those who currently smoke versus those who do not currently smoke), exercise behavior (those who have exercised in the last month versus those who have not), diagnosed depression, diagnosed anxiety, and the Charlson comorbidity index (CCI). The CCI is a single score which captures the overall comorbidity burden of each patient. ${ }^{10}$

\section{Health status}

The Medical Outcomes Study 12-Item Short Form Survey Instrument version $2(\mathrm{SF}-12 \mathrm{v} 2)$ is an instrument used to assess health status, and has strong evidence of validity. ${ }^{11}$ The SF-12v2 instrument includes two summary scores (ie, physical [PCS] and mental component summary [MCS] scores) and a health utility index (Short Form 6 Dimensions, SF-6D). PCS and MCS scores each have a population mean of 50, along with a standard deviation of 10 (higher scores indicate better quality of life). ${ }^{11}$ Past research has suggested that a three-point difference in PCS and MCS is clinically meaningful. ${ }^{12}$ The health utility index has interval scoring properties and yields a summary score on a theoretical $0-1$ scale, with differences of 0.03 points being clinically meaningful. ${ }^{13}$ As discussed elsewhere, the definition of clinical meaning for these measures has either been defined by their effect sizes and/or by anchoring change on the health status measures with a clinical outcome relevant to the particular conditions of interest. ${ }^{14}$

\section{Work productivity}

The Work Productivity and Activity Impairment questionnaire was used to measure the impact of health on work productivity loss and impairment in daily activities. ${ }^{15}$ The Work Productivity and Activity questionnaire is a six-item instrument that consists of four metrics: absenteeism (the percentage of work time missed because of one's health in the past 7 days), presenteeism (the percentage of impairment experienced while at work in the past 7 days because of one's health), overall work productivity loss (an overall impairment estimate that is a combination of absenteeism and presenteeism), and activity impairment (the percentage of impairment in daily activities because of one's health in the past 7 days). Only respondents who reported being employed full-time, employed part-time, or self-employed provided data for absenteeism, presenteeism, and overall work impairment. All respondents provided data for activity impairment. This instrument has been used previously among patients with IBS-C. ${ }^{16}$

\section{Health care resource utilization}

Health care resource use was assessed by the number of visits to the general practitioner, specialists, the emergency room, and to the hospital for the patient's medical condition in the previous 6 months. All variables were self-reported by the patient.

\section{Statistical analysis}

Because of systematic epidemiological differences within IBS-C and variability in health care systems and resource utilization across France, Italy, and the UK, statistical analyses were conducted separately for each of these three countries. Within each country, patients with IBS-C were compared with patients without IBS-C for sociodemographics and health history. These differences were tested using Chi-square tests for categorical outcomes and $t$-tests for continuous outcomes. To isolate the burden specific to IBS-C properly, a propensity score-matching technique was used. Based on observed differences between groups, subject age, gender, body mass index, alcohol use, and the CCI were included as variables in the matching process. Differences in anxiety and depression were observed, but because IBS-C may have contributed to the appearance of these conditions, they were not considered for inclusion as part of the matching process. ${ }^{17}$

Therefore, age, gender, body mass index, alcohol use, and $\mathrm{CCI}$ were entered into a logistic regression to predict IBS-C versus non-IBS-C status. The propensity score values were saved from this model. Using these values, each IBS-C patient was matched with three non-IBS-C patients (matched controls, hereafter) whose propensity score values were closest using a greedy matching algorithm. After the matching process was completed, patients with IBS-C and matched controls were compared with respect to health status, work productivity and activity impairment, and health care resource utilization variables were compared using independent-samples $t$-tests.

Sensitivity analyses were performed by repeating the same matching approach described above but excluding the CCI. Following matching, patients with IBS-C and matched controls were compared with respect to health status, work productivity, and activity impairment, and health care resource utilization variables using independent-samples $t$-tests. Because IBS-C may exacerbate the presence of other comorbidities, controlling for the CCI may slightly underestimate the true marginal effect of IBS-C. Removing the $\mathrm{CCI}$ from the matching process may overestimate the effect of IBS-C, but would provide a less conservative estimate of 
the effect of IBS-C. All analyses were conducted using SAS version 9.1 (SAS Inc, Cary, NC). Statistical significance was set a priori to a two-tailed $P<0.05$.

\section{Results}

A total of $83(0.55 \%), 109(1.44 \%)$, and $204(1.35 \%)$ respondents reported a diagnosis of IBS with only constipation symptoms for France, Italy, and the UK, respectively. These patients were compared with 14,705, 13,834, and 7121 respondents, respectively, who did not report a diagnosis of IBS.

\section{Comparisons between patients with IBS-C and unmatched controls}

In France, patients with IBS-C were generally similar to patients without IBS-C (see Table 1). However, these patients were significantly more likely to be female $(85.54 \%$ versus $55.25 \%, P<0.0001$ ), were significantly older (48.54 years versus 45.02 years, $P=0.039$ ), and had a greater comorbidity burden $(0.42$ versus $0.23, P=0.006)$. Patients with
IBS-C were also more likely to report diagnosed depression (26.51\% versus $8.00 \%, P=0.0004)$ and diagnosed anxiety (55.42\% versus $18.69 \%, P<0.0001)$. Patients with IBS-C in the UK were, as with the other countries, significantly more likely to be female (73.04\% versus $48.23 \%, P<0.0001)$, to report diagnosed depression $(36.27 \%$ versus $14.98 \%$, $P<0.0001)$, and to report diagnosed anxiety (38.24\% versus $14.01 \%, P<0.0001$, see Table 2 ). These patients also reported a greater comorbidity burden and were significantly less likely to use alcohol currently $(73.53 \%$ versus $84.17 \%$, $P=0.0009)$. A similar pattern was observed in Italy, because patients with IBS-C were significant more likely to be female (79.82\% versus $46.00 \%, P<0.0001)$, to be of normal weight (65.14\% versus $47.37 \%, P=0.0003)$, to report diagnosed depression (12.84\% versus $6.36 \%, P=0.048)$, and to report diagnosed anxiety $(34.86 \%$ versus $13.38 \%$, $P<0.0001$ ) relative to patients without IBS-C (see Table 3 ). No differences were observed with respect to age and overall comorbidity burden.

Table I Differences between patients with IBS-C and unmatched controls with respect to sociodemographics and health history in France

\begin{tabular}{|c|c|c|c|c|c|c|c|}
\hline & \multicolumn{3}{|c|}{$\begin{array}{l}\text { IBS-C group } \\
(n=83)\end{array}$} & \multicolumn{3}{|c|}{$\begin{array}{l}\text { Unmatched control group } \\
(n=\mid 4,705)\end{array}$} & \multirow[t]{2}{*}{$P$} \\
\hline & $n$ & $\%$ & SE & $\mathbf{n}$ & $\%$ & SE & \\
\hline \multicolumn{8}{|l|}{ Gender } \\
\hline Male & 12 & $14.46 \%$ & $\pm 3.86 \%$ & 6581 & $44.75 \%$ & $\pm 0.41 \%$ & $<0.000 \mathrm{I}$ \\
\hline \multicolumn{8}{|l|}{ Education } \\
\hline University educated & 29 & $34.94 \%$ & $\pm 5.23 \%$ & 6441 & $43.80 \%$ & $\pm 0.41 \%$ & 0.0969 \\
\hline \multicolumn{8}{|l|}{ Annual household income } \\
\hline Below country median & 48 & $57.83 \%$ & $\pm 5.42 \%$ & 7831 & $53.25 \%$ & $\pm 0.41 \%$ & 0.4018 \\
\hline Above country median & 22 & $26.51 \%$ & $\pm 4.84 \%$ & 5180 & $35.23 \%$ & $\pm 0.39 \%$ & 0.0783 \\
\hline Missing income & 13 & $15.66 \%$ & $\pm 3.99 \%$ & 1694 & $11.52 \%$ & $\pm 0.26 \%$ & 0.3032 \\
\hline \multicolumn{8}{|l|}{ Body mass index } \\
\hline Underweight & 6 & $7.23 \%$ & $\pm 2.84 \%$ & 548 & $3.73 \%$ & $\pm 0.16 \%$ & 0.2227 \\
\hline Normal weight & 44 & $53.01 \%$ & $\pm 5.48 \%$ & 7139 & $48.55 \%$ & $\pm 0.41 \%$ & 0.4183 \\
\hline Overweight & 20 & $24.10 \%$ & $\pm 4.69 \%$ & 4500 & $30.60 \%$ & $\pm 0.38 \%$ & 0.172 \\
\hline Obese & 9 & $10.84 \%$ & $\pm 3.41 \%$ & 2280 & $15.50 \%$ & $\pm 0.3 \%$ & 0.1783 \\
\hline Missing weight & 4 & $4.82 \%$ & $\pm 2.35 \%$ & 238 & $1.62 \%$ & $\pm 0.1 \%$ & 0.1785 \\
\hline \multicolumn{8}{|l|}{ Comorbidities } \\
\hline Diagnosed depression & 22 & $26.51 \%$ & $\pm 4.84 \%$ & 1176 & $8.00 \%$ & $\pm 0.22 \%$ & 0.0004 \\
\hline Diagnosed anxiety & 46 & $55.42 \%$ & $\pm 5.46 \%$ & 2748 & $18.69 \%$ & $\pm 0.32 \%$ & $<0.000 \mathrm{I}$ \\
\hline \multicolumn{8}{|l|}{ Health behaviors } \\
\hline Current alcohol use & 61 & $73.49 \%$ & $\pm 4.84 \%$ & 11491 & $78.14 \%$ & $\pm 0.34 \%$ & $0.34 I$ \\
\hline Current smoker & 32 & $38.55 \%$ & $\pm 5.34 \%$ & 4571 & $31.08 \%$ & $\pm 0.38 \%$ & 0.168 \\
\hline Regularly exercise & $4 I$ & $49.40 \%$ & $\pm 5.49 \%$ & 7903 & $53.74 \%$ & $\pm 0.41 \%$ & 0.4314 \\
\hline \multicolumn{8}{|l|}{ Labor force participation } \\
\hline \multirow[t]{2}{*}{ In the labor force } & 40 & $48.19 \%$ & $\pm 5.48 \%$ & 9074 & $61.71 \%$ & $\pm 0.4 \%$ & 0.0176 \\
\hline & $\mathbf{n}$ & Mean & SD & $\mathbf{n}$ & Mean & SD & $P$ \\
\hline Age & 83 & 48.54 & 15.55 & 14705 & 45.02 & 15.54 & 0.0393 \\
\hline Charlson comorbidity index & 83 & 0.42 & 0.84 & 14705 & 0.23 & 0.62 & 0.0055 \\
\hline
\end{tabular}

Abbreviations: IBS-C, irritable bowel syndrome constipation subtype; SD, standard deviation; SE, standard error of the mean. 
Table 2 Differences between patients with IBS-C and unmatched controls with respect to sociodemographics and health history in the UK

\begin{tabular}{|c|c|c|c|c|c|c|c|}
\hline & \multicolumn{3}{|c|}{$\begin{array}{l}\text { IBS-C group } \\
(n=204)\end{array}$} & \multicolumn{3}{|c|}{$\begin{array}{l}\text { Unmatched control group } \\
(n=13,834)\end{array}$} & \multirow[t]{2}{*}{$P$} \\
\hline & $\mathbf{n}$ & $\%$ & SE & $\mathbf{n}$ & $\%$ & SE & \\
\hline \multicolumn{8}{|l|}{ Gender } \\
\hline Male & 55 & $26.96 \%$ & $\pm 3.11 \%$ & 7162 & $51.77 \%$ & $\pm 0.42 \%$ & $<0.0001$ \\
\hline \multicolumn{8}{|l|}{ Education } \\
\hline University educated & 102 & $50.00 \%$ & $\pm 3.5 \%$ & 7015 & $50.71 \%$ & $\pm 0.43 \%$ & 0.8408 \\
\hline \multicolumn{8}{|l|}{ Annual household income } \\
\hline Below country median & 83 & $40.69 \%$ & $\pm 3.44 \%$ & 6335 & $45.79 \%$ & $\pm 0.42 \%$ & 0.1426 \\
\hline Above country median & 100 & $49.02 \%$ & $\pm 3.5 \%$ & 5866 & $42.40 \%$ & $\pm 0.42 \%$ & 0.0627 \\
\hline Missing income & 21 & $10.29 \%$ & $\pm 2.13 \%$ & 1633 & $11.80 \%$ & $\pm 0.27 \%$ & 0.482 \\
\hline \multicolumn{8}{|l|}{ Body mass index } \\
\hline Underweight & 7 & $3.43 \%$ & $\pm 1.27 \%$ & 312 & $2.26 \%$ & $\pm 0.13 \%$ & 0.3595 \\
\hline Normal weight & 84 & $41.18 \%$ & $\pm 3.45 \%$ & 4878 & $35.26 \%$ & $\pm 0.41 \%$ & 0.0904 \\
\hline Overweight & 65 & $31.86 \%$ & $\pm 3.26 \%$ & 4678 & $33.82 \%$ & $\pm 0.4 \%$ & 0.5529 \\
\hline Obese & 40 & $19.61 \%$ & $\pm 2.78 \%$ & 3236 & $23.39 \%$ & $\pm 0.36 \%$ & 0.1789 \\
\hline Missing weight & 8 & $3.92 \%$ & $\pm 1.36 \%$ & 730 & $5.28 \%$ & $\pm 0.19 \%$ & 0.3245 \\
\hline \multicolumn{8}{|l|}{ Comorbidities } \\
\hline Diagnosed depression & 74 & $36.27 \%$ & $\pm 3.37 \%$ & 2073 & $14.98 \%$ & $\pm 0.3 \%$ & $<0.0001$ \\
\hline Diagnosed anxiety & 78 & $38.24 \%$ & $\pm 3.4 \%$ & 1938 & $14.01 \%$ & $\pm 0.3 \%$ & $<0.0001$ \\
\hline \multicolumn{8}{|l|}{ Health behaviors } \\
\hline Current alcohol use & 150 & $73.53 \%$ & $\pm 3.09 \%$ & 11644 & $84.17 \%$ & $\pm 0.31 \%$ & 0.0009 \\
\hline Current smoker & 47 & $23.04 \%$ & $\pm 2.95 \%$ & 2970 & $21.47 \%$ & $\pm 0.35 \%$ & 0.5971 \\
\hline Regularly exercise & 127 & $62.25 \%$ & $\pm 3.39 \%$ & 8248 & $59.62 \%$ & $\pm 0.42 \%$ & 0.4418 \\
\hline \multicolumn{8}{|l|}{ Labor force participation } \\
\hline \multirow[t]{2}{*}{ In the labor force } & 123 & $60.29 \%$ & $\pm 3.43 \%$ & 8301 & $60.00 \%$ & $\pm 0.42 \%$ & 0.9331 \\
\hline & $\mathbf{n}$ & Mean & SD & $\mathbf{n}$ & Mean & SD & $P$ \\
\hline Age & 204 & 45.76 & 14.87 & 13834 & 47.66 & 16.59 & 0.1046 \\
\hline Charlson comorbidity index & 204 & 0.69 & 3.27 & 13834 & 0.28 & 0.74 & $<0.000$ I \\
\hline
\end{tabular}

Abbreviations: IBS-C, irritable bowel syndrome constipation subtype; SD, standard deviation; SE, standard error of the mean.

\section{Comparisons between patients with IBS-C and matched controls}

After matching for demographic and health history differences, patients with IBS-C in France reported significantly worse mean health status (MCS 39.77 versus 46.57, $P<0.0001$; PCS 43.72 versus $47.95, P=0.0016$; mean health utility score 0.63 versus $0.71, P<0.0001$, see Table 4$)$. These between-group differences exceeded clinically relevant cutoff values of 3 and 0.03 points for MCS/PCS and health utilities, respectively. These patients also reported significantly more mean general practice (3.78 versus $2.65 ; P=0.0044$ ) and specialist visits ( 7.02 versus $4.04 ; P=0.0032)$ per 6 months, which would equate to $43 \%$ and $74 \%$ more visits to general practitioners and specialists, respectively, per year. Although trends were observed with respect to emergency room visits and hospitalizations, these differences were not statistically significant. IBS-C patients in France who were currently employed also reported significantly greater mean overall work impairment in the past week than matched controls who were currently employed (34.15\% versus $19.73 \%$;
$P=0.0214)$. This would equate to $73 \%$ more work time lost per year due to either absenteeism or presenteeism. Among all IBS-C patients, regardless of employment status, higher rates of activity impairment were observed relative to matched controls ( $40.00 \%$ versus $25.54 \% ; P=0.0001)$.

A similar pattern was observed in the UK in terms of mean health status (MCS 41.62 versus 44.50, $P=0.0026$; PCS 44.31 versus $48.90, P<0.0001$; mean health utility scores 0.65 versus $0.72, P<0.0001$, see Table 5). Again, the size of these effects exceeded clinically meaningful levels. Patients with IBS-C made significantly more mean general practice (2.98 versus $1.95 ; P<0.0001)$ and specialist $(3.76$ versus $2.48 ; P=0.0009)$ visits, and had more hospitalizations per 6 months $(0.20$ versus $0.11 ; P=0.0456)$ compared with matched controls. These figures correspond to $53 \%, 52 \%$, and $82 \%$ more general practice visits, specialist visits, and hospitalizations, respectively. Although more emergency room visits were also reported by patients with IBS-C, this was not significantly different from matched controls. Predominantly due to increased presenteeism, mean overall 
Table 3 Differences between patients with IBS-C and unmatched controls with respect to sociodemographics and health history in Italy

\begin{tabular}{|c|c|c|c|c|c|c|c|}
\hline & \multicolumn{3}{|c|}{$\begin{array}{l}\text { IBS-C group } \\
(n=109)\end{array}$} & \multicolumn{3}{|c|}{$\begin{array}{l}\text { Unmatched control group } \\
(n=7 \mid 2 I)\end{array}$} & \multirow[t]{2}{*}{$\boldsymbol{P}$} \\
\hline & $\mathbf{n}$ & $\%$ & SE & $\mathbf{n}$ & $\%$ & SE & \\
\hline \multicolumn{8}{|l|}{ Gender } \\
\hline Male & 22 & $20.18 \%$ & $\pm 3.84 \%$ & 3845 & $54.00 \%$ & $\pm 0.59 \%$ & $<0.0001$ \\
\hline \multicolumn{8}{|l|}{ Education } \\
\hline University educated & $4 I$ & $37.61 \%$ & $\pm 4.64 \%$ & 2167 & $30.43 \%$ & $\pm 0.55 \%$ & 0.1281 \\
\hline \multicolumn{8}{|l|}{ Annual household income } \\
\hline Below country median & 49 & $44.95 \%$ & $\pm 4.77 \%$ & 2921 & $41.02 \%$ & $\pm 0.58 \%$ & 0.4138 \\
\hline Above country median & 49 & $44.95 \%$ & $\pm 4.77 \%$ & 3013 & $42.31 \%$ & $\pm 0.59 \%$ & 0.5825 \\
\hline Missing income & II & $10.09 \%$ & $\pm 2.89 \%$ & 1187 & $16.67 \%$ & $\pm 0.44 \%$ & 0.0275 \\
\hline \multicolumn{8}{|l|}{ Body mass index } \\
\hline Underweight & 5 & $4.59 \%$ & $\pm 2 \%$ & 233 & $3.27 \%$ & $\pm 0.21 \%$ & 0.5148 \\
\hline Normal weight & 71 & $65.14 \%$ & $\pm 4.56 \%$ & 3373 & $47.37 \%$ & $\pm 0.59 \%$ & 0.0003 \\
\hline Overweight & 27 & $24.77 \%$ & $\pm 4.14 \%$ & 2443 & $34.31 \%$ & $\pm 0.56 \%$ & 0.0255 \\
\hline Obese & 6 & $5.50 \%$ & $\pm 2.18 \%$ & 981 & $13.78 \%$ & $\pm 0.41 \%$ & 0.0004 \\
\hline Missing weight & 0 & $0.00 \%$ & $\pm 0.00 \%$ & 91 & $1.28 \%$ & $\pm 0.13 \%$ & - \\
\hline \multicolumn{8}{|l|}{ Comorbidities } \\
\hline Diagnosed depression & 14 & $12.84 \%$ & $\pm 3.2 \%$ & 453 & $6.36 \%$ & $\pm 0.29 \%$ & 0.0478 \\
\hline Diagnosed anxiety & 38 & $34.86 \%$ & $\pm 4.56 \%$ & 953 & $13.38 \%$ & $\pm 0.4 \%$ & $<0.0001$ \\
\hline \multicolumn{8}{|l|}{ Health behaviors } \\
\hline Current alcohol use & 73 & $66.97 \%$ & $\pm 4.51 \%$ & 4931 & $69.25 \%$ & $\pm 0.55 \%$ & 0.6168 \\
\hline Current smoker & 25 & $22.94 \%$ & $\pm 4.03 \%$ & 1867 & $26.22 \%$ & $\pm 0.52 \%$ & 0.4203 \\
\hline Regularly exercise & 64 & $58.72 \%$ & $\pm 4.72 \%$ & 3892 & $54.66 \%$ & $\pm 0.59 \%$ & 0.3945 \\
\hline \multicolumn{8}{|l|}{ Labor force participation } \\
\hline \multirow[t]{2}{*}{ In the labor force } & 70 & $64.22 \%$ & $\pm 4.59 \%$ & 4513 & $63.38 \%$ & $\pm 0.57 \%$ & 0.8552 \\
\hline & $\mathbf{n}$ & Mean & SD & $\mathbf{n}$ & Mean & SD & $P$ \\
\hline Age & 109 & 48.15 & 14.74 & 7121 & 48.86 & 15.47 & 0.6346 \\
\hline Charlson comorbidity index & 109 & 0.27 & 0.63 & $7|2|$ & 0.27 & 0.73 & 0.9183 \\
\hline
\end{tabular}

Abbreviations: IBS-C, irritable bowel syndrome constipation subtype; SD, standard deviation; SE, standard error of the mean.

work impairment $(29.46 \%$ versus $21.88 \% ; P=0.0242)$ was significantly greater among employed patients with IBS-C, corresponding to $35 \%$ more work impairment on an annual basis for these patients. Mean activity impairment was also greater $(36.57 \%$ versus $27.16 \% ; P=0.0002)$.

IBS-C patients in Italy reported a health status decline similar to that of their French and UK counterparts (MCS 41.79 versus 44.93, $P=0.0043$; PCS 43.72 versus 47.95, $P=0.0016$; mean health utility scores 0.63 versus 0.71 , $P<0.0001$, see Table 6). All health status effects were above clinically relevant thresholds. In contrast with other countries, IBS-C patients in Italy did not report significantly more mean work loss on any measure. Increased resource utilization was observed, but in terms of general practice (IBS-C 4.84 versus matched control 2.33; $P<0.0001$ ) and specialist (IBS-C 5.28 versus matched control 3.08; $P=0.0001)$ visits per 6 months. These values correspond to $108 \%$ and $71 \%$ more visits, respectively to these providers. The presence of IBS-C was not associated with differences in either emergency room visits or hospitalizations.

\section{Sensitivity analyses}

Sensitivity analysis results (excluding the comorbidity index) showed consistency with the main analyses, although all effects were stronger, as anticipated. For example, in France, health utility scores were significantly lower among those with IBS-C (0.63 versus $0.73, P<0.0001$ ), and overall work impairment was significantly higher $(15.66 \%$ versus $34.15 \%, P=0.0011)$. In contrast with the main analyses, almost all resource use variables were significantly greater in the IBS-C group in these sensitivity analyses (hospitalizations 0.31 versus 0.10 , general practice visits 3.78 versus 2.57 , specialist visits 7.02 versus 3.2 , all $P<0.05)$. Emergency room visits were marginally significant (emergency room visits 0.18 versus $0.07, P=0.06$ ).

The results of the UK sensitivity analyses were similar to those of the main analyses. Although the size of the differences between groups increased, the statistical conclusions were identical: those with IBS-C reported significantly worse health utility scores compared with matched controls $(0.65$ versus $0.72, P<0.0001)$ and significantly more overall work impairment $(19.21 \%$ versus $30.93 \%$, 
Table 4 Health outcome differences between patients with IBS-C and matched controls in France

\begin{tabular}{|c|c|c|c|c|c|c|c|}
\hline & \multicolumn{3}{|c|}{$\begin{array}{l}\text { IBS-C group } \\
(n=83)\end{array}$} & \multicolumn{3}{|c|}{$\begin{array}{l}\text { Matched control } \\
(n=249)\end{array}$} & \multirow[t]{2}{*}{$\mathbf{P}$} \\
\hline & $\mathbf{n}$ & Mean & SD & $\mathbf{n}$ & Mean & SD & \\
\hline SF-I2: mental component summary score & 83 & 39.77 & 11.72 & 249 & 46.57 & 10.54 & $<0.000 \mathrm{I}$ \\
\hline SF-12: physical component summary score & 83 & 43.72 & 12.02 & 249 & 47.95 & 9.95 & 0.0016 \\
\hline SF-6D: health utility score & 83 & 0.63 & 0.14 & 249 & 0.71 & 0.14 & $<0.0001$ \\
\hline Number of GP visits per 6 months & 83 & 3.78 & 3.04 & 249 & 2.65 & 3.08 & 0.004 \\
\hline Number of specialist visits per 6 months & 83 & 7.02 & 9.74 & 249 & 4.04 & 7.23 & 0.0032 \\
\hline Number of ER visits per 6 months & 83 & 0.18 & 0.50 & 249 & 0.13 & 0.67 & 0.5495 \\
\hline Number of hospitalizations per 6 months & 83 & 0.31 & 0.96 & 249 & 0.14 & 0.71 & 0.0737 \\
\hline Absenteeism \% & 33 & 13.21 & 31.29 & 124 & 8.65 & 24.89 & 0.3783 \\
\hline Hours missed due to absenteeism per week & 33 & 5.45 & 12.98 & 126 & 3.75 & 11.91 & 0.4726 \\
\hline Presenteeism \% & 30 & 26.00 & 26.08 & 117 & 13.85 & 22.28 & 0.0111 \\
\hline Hours missed due to presenteeism per week & 30 & 8.09 & 8.63 & 117 & 4.37 & 7.32 & 0.0179 \\
\hline Overall work impairment $\%$ & 33 & 34.15 & 33.81 & 124 & 19.73 & 31.11 & 0.0214 \\
\hline Activity impairment \% & 83 & 40.00 & 32.27 & 249 & 25.54 & 28.78 & 0.0001 \\
\hline
\end{tabular}

Abbreviations: ER, emergency room; GP, general practice; SD, standard deviation; SF-12, Short Form-12; SF-6D, Short Form 6 Dimensions; IBS-C, irritable bowel syndrome constipation subtype.

$P=0.0002)$, general practice visits $(3.00$ versus 1.86 $P<0.0001$ ), specialist visits (4.13 versus $2.41, P=0.002$ ), and hospitalizations ( 0.26 versus $0.10, P=0.001)$. As in the UK, the sensitivity analyses conducted in Italy were nearly identical to the main analyses. Health utilities were significantly lower among those with IBS-C ( 0.66 versus $0.70, P<0.0001)$ and the number of general practice $(4.84$ versus $2.27, P<0.0001)$ and specialist visits $(5.28$ versus $2.92, P<0.0001)$ were significantly higher. Although these findings were consistent with the main analyses, the difference in the percentage of overall work impairment between groups was significant in the sensitivity analyses (IBS-C $28.06 \%$ versus matched control $19.37 \%, P=0.018$ ), but not in the main analyses.

\section{Discussion}

Several studies have previously examined the burden of IBS with respect to health status, health care resource utilization, and work productivity. However, these studies have investigated IBS generally and have not examined the specific constipation-predominant subtype. The aim of this study was to address this gap by quantifying the burden experienced by IBS-C patients in France, Italy, and the UK.

The current study estimated the prevalence of diagnosed IBS with constipation symptoms as $0.55 \%, 1.44 \%$, and $1.35 \%$ for France, Italy, and the UK, respectively. Comparisons with the literature are difficult because, to our knowledge, no population-based study of IBS-C has been conducted in Western Europe. Nevertheless, assuming a prevalence of

Table 5 Health outcome differences between patients with IBS-C and matched controls in the UK

\begin{tabular}{|c|c|c|c|c|c|c|c|}
\hline & \multicolumn{3}{|c|}{$\begin{array}{l}\text { IBS-C group } \\
(n=20 I)\end{array}$} & \multicolumn{3}{|c|}{$\begin{array}{l}\text { Matched control } \\
(n=603)\end{array}$} & \multirow[t]{2}{*}{$P$} \\
\hline & $\mathrm{n}$ & Mean & SD & $\mathbf{n}$ & Mean & SD & \\
\hline SF-I2: mental component summary score & 201 & 41.62 & $1 \mathrm{I} .87$ & 603 & 44.50 & 11.68 & 0.0026 \\
\hline SF-12: physical component summary score & 201 & 44.31 & 13.52 & 603 & 48.90 & $1 \mathrm{I} .40$ & $<0.000$ I \\
\hline SF-6D: health utility score & 201 & 0.65 & 0.14 & 603 & 0.72 & 0.14 & $<0.0001$ \\
\hline Number of GP visits per 6 months & 201 & 2.98 & 3.46 & 603 & 1.95 & 2.80 & $<0.000$ I \\
\hline Number of specialist visits per 6 months & 201 & 3.76 & 6.18 & 603 & 2.48 & 4.12 & 0.0009 \\
\hline Number of ER visits per 6 months & 201 & 0.32 & 0.92 & 603 & 0.23 & 1.05 & 0.2624 \\
\hline Number of hospitalizations per 6 months & 201 & 0.20 & 0.70 & 603 & 0.11 & 0.54 & 0.0456 \\
\hline Absenteeism \% & 103 & 6.70 & 19.41 & 318 & 6.30 & 21.19 & 0.8651 \\
\hline Hours missed due to absenteeism per week & 112 & 1.79 & 5.07 & 337 & 1.90 & 6.72 & 0.8835 \\
\hline Presenteeism \% & 102 & 26.47 & 29.03 & 306 & 17.35 & 22.57 & 0.0011 \\
\hline Hours missed due to presenteeism per week & 101 & 7.53 & 9.46 & 306 & 5.23 & 7.80 & 0.0158 \\
\hline Overall work impairment \% & 103 & 29.46 & 31.94 & 318 & 21.88 & 28.71 & 0.0242 \\
\hline Activity impairment \% & 201 & 36.57 & 32.69 & 603 & 27.16 & 30.22 & 0.0002 \\
\hline
\end{tabular}

Abbreviations: ER, emergency room; GP, general practice; SD, standard deviation; SF-12, Short Form-12; SF-6D, Short Form 6 Dimensions; IBS-C, irritable bowel syndrome constipation subtype. 
Table 6 Health outcome differences between patients with IBS-C and matched controls in Italy

\begin{tabular}{|c|c|c|c|c|c|c|c|}
\hline & \multicolumn{3}{|c|}{$\begin{array}{l}\text { IBS-C group } \\
(n=109)\end{array}$} & \multicolumn{3}{|c|}{$\begin{array}{l}\text { Matched control } \\
(n=327)\end{array}$} & \multirow[t]{2}{*}{$P$} \\
\hline & $\mathrm{n}$ & Mean & SD & $\mathrm{n}$ & Mean & SD & \\
\hline SF-12: mental component summary score & 109 & 41.79 & 9.86 & 327 & 44.93 & 9.92 & 0.0043 \\
\hline SF-12: physical component summary score & 109 & 46.03 & 8.79 & 327 & 48.06 & 8.76 & 0.037 \\
\hline SF-6D: health utility score & 109 & 0.66 & 0.1 & 327 & 0.70 & 0.11 & 0.0016 \\
\hline Number of GP visits per 6 months & 109 & 4.84 & 6.23 & 327 & 2.33 & 3.36 & $<0.0001$ \\
\hline Number of specialist visits per 6 months & 109 & 5.28 & 7.36 & 327 & 3.08 & 4.19 & 0.0001 \\
\hline Number of ER visits per 6 months & 109 & 0.37 & 1.03 & 327 & 0.37 & 3.60 & 0.9861 \\
\hline Number of hospitalizations per 6 months & 109 & 0.11 & 0.44 & 327 & 0.07 & 0.37 & 0.3914 \\
\hline Absenteeism \% & 67 & 5.51 & 18.15 & 210 & 2.26 & 8.88 & 0.0508 \\
\hline Hours missed due to absenteeism per week & 67 & 2.22 & 8.46 & 215 & 0.81 & 3.78 & 0.057 \\
\hline Presenteeism \% & 65 & 24.77 & 26.58 & 210 & 19.81 & 23.88 & 0.1556 \\
\hline Hours missed due to presenteeism per week & 65 & 7.90 & 9.12 & 210 & 6.87 & 8.82 & $0.4|7|$ \\
\hline Overall work impairment $\%$ & 67 & 28.06 & 30.11 & 210 & 20.93 & 25.28 & 0.0565 \\
\hline Activity impairment \% & 109 & 31.83 & 29.76 & 327 & 25.84 & 27.67 & 0.0553 \\
\hline
\end{tabular}

Abbreviations: ER, emergency room; GP, general practice; SD, standard deviation; SF-12, Short Form-I2; SF-6D, Short Form 6 Dimensions; IBS-C, irritable bowel syndrome constipation subtype.

$4.8 \%$ of diagnosed $\mathrm{IBS}^{2}$ and assuming a third of those patients with IBS are constipation-predominant, ${ }^{2}$ then these population estimates are in range of what might be expected from the literature (1.6\%). However, as reported elsewhere, substantial variability was observed across countries. ${ }^{2}$ Dividing diagnosed country-specific IBS prevalence by three, estimated diagnosed IBS-C prevalence would be $1.07 \%, 3.83 \%$, and $2.23 \%$ for France, Italy, and the UK. Although relationally consistent, these latter estimates are higher than those observed in the present study. These differences could be due to the imprecision of estimating constipation-predominance (34\%) across all countries (perhaps the constipationpredominant subtype is less prevalent in France, Italy, and the UK). Additionally, the fact that the NHWS is a broader health survey and the survey in Hungin et al was IBS-specific may have influenced the types of respondents who agreed to take part. $^{2}$ Finally, the NHWS is more recent (2010 versus 2003), which may suggest changing epidemiological trends in Western Europe. Further research is necessary.

Consistent with the large amount of literature on IBS and health status, our study found that patients with IBS-C reported significantly worse physical and mental component summary scores relative to matched controls. These effects were consistently above clinically meaningful cutoffs, suggesting substantial detriment to the daily functioning of these patients. Interestingly, the effects were generally stronger from a mental health status perspective than from the physical one, suggesting that patients suffer a profound emotional and psychological toll when dealing with IBS-C. Our results are generally consistent with other IBS studies in Western Europe. ${ }^{3-5}$ To put these results in a broader context, analyses of other conditions using the same NHWS data source suggest that the health status (as assessed using health utilities) of patients with IBS-C is worse than patients with diabetes, ${ }^{18}$ peripheral arterial disease, ${ }^{19}$ or gout. ${ }^{20}$ Other studies have also suggested the burden of IBS-C is comparable with or worse than gastroesophageal reflux disease, asthma, and migraine. ${ }^{21}$

Patients with IBS-C also reported significantly greater health care resource use, although this was primarily due to increased general practice and specialist visits. On average, patients with IBS-C reported visiting their general practitioners $43 \%$ more often in France, 53\% more often in the UK, and 108\% more often in Italy (in the last 6 months). Specialist visits were also more frequent compared with matched controls: $74 \%$ in France, $52 \%$ in the UK, and $71 \%$ in Italy. Hospitalizations were more frequent in the UK $(82 \%$ more often) and France, though not significantly so for the latter (121\% greater; $P=0.07)$. Differences in emergency room utilization were not observed. Although prior studies have not investigated resource use within IBS-C specifically, our results are consistent with trends for IBS more generally in Western Europe, which has suggested frequent resource utilization, particularly with respect to physician visits and hospitalizations. Cost analyses were not within the scope of the current project, but there is a clear implication of substantial direct costs from a societal perspective attributed to IBS-C.

We also observed a burden of IBS-C as it relates to work productivity (with the exception of Italy), although this was generally limited to presenteeism. This contrasts slightly with the literature on IBS as reviewed by 
Maxion-Bergemann et al, ${ }^{6}$ where both absenteeism and presenteeism differences were observed. Part of these differences may be due to a statistical power issue, given that the size of the absenteeism differences (53\%, 6\%, and 144\% more absenteeism among IBS-C patients in France, Italy, and the UK, respectively) was similar overall to that observed by Hungin et $\mathrm{al}^{2}$ (77\% more). Presenteeism effects were also somewhat similar (although lower), despite the different approaches to measurement, because we reported $88 \%, 53 \%$, and 25\% more presenteeism among IBS-C patients in France, Italy, and the UK, respectively, and Hungin et $\mathrm{al}^{2}$ reported $113 \%$ more presenteeism. Of course, due to our matching methodology (which accounted for age and comorbidity differences, among others), it is expected that our results would provide a lower estimate of the marginal burden of IBS-C compared with the literature. Given that patients with IBS-C are generally in their peak earning years, there are substantial societal cost implications if these patients are unable to function productively while at work.

The results of the sensitivity analyses, in which comorbidities were not adjusted for as potential confounders, were consistent with the main analyses, although with slightly larger effect sizes. The results suggest that conditions that co-occur with IBS-C also have substantial effects on health status, resource utilization, and productivity. Because these conditions may be exacerbated by or present independently of IBS-C, the true effect size of IBS-C on the outcomes under investigation can be thought of as bounded by the effect sizes observed in the main analyses (lower bound) and those observed in the sensitivity analyses (upper bound).

Collectively, these results highlight the significant burden of patients who report a diagnosis of IBS-C in France, Italy, and the UK. These findings highlight the pervasive influence of IBS-C on the day-to-day functioning of patients, their ability to be productive at work, and their influence on the wider health care system. Significant unmet needs remain, and improved management of this condition could result in significant and clinically meaningful gains in health status as well as alleviate a societal cost burden. Although perhaps not a traditional focus in patient management, our results suggest the effect of IBS-C is more substantial, from a health status perspective, that other major chronic conditions, such as gastroesophageal reflux disease, asthma, and migraine.

\section{Limitations}

The limitations of this research should be noted. The NHWS is self-reported, so diagnoses were not validated through objective means. Although this approach is consistent with other large-scale, population-based studies, ${ }^{2}$ it does present the potential for misclassification. Patients in the IBS-C group may not, in fact, have IBS-C and matched controls may have IBS-C. Indeed, it may even be difficult in clinical practice to distinguish between those with IBS-C and constipation. It is unclear the extent to which these findings generalize to IBS-C specifically (as opposed to related conditions) and further research would be necessary. The issue of self-reporting also extends to the outcome measures, because health care resource use may vary from objective values because of recall biases. The NHWS is broadly representative based on the age and gender of each country's population. However, it is possible that the specific IBS-C subgroup explored here may differ from the IBS-C population in meaningful ways.

\section{Acknowledgment}

The authors would like to thank Jan-Samuel Wagner for his contribution to the literature review.

\section{Disclosure}

The National Health and Wellness Survey is conducted by Kantar Health (New York, NY). Almirall purchased access to the data and funded the analysis and preparation of this manuscript. MDD is a current employee of Kantar Health, and MP, PP, and JF are current employees of Almirall.

\section{References}

1. Drossman DA, Chang L, Bellamy N, et al. Severity in irritable bowel syndrome: a Rome Foundation Working Team report. Am J Gastroenterol. 2011;106:1749-1759.

2. Hungin AP, Whorwell PJ, Tack J, Mearin F. The prevalence, patterns and impact of irritable bowel syndrome: an international survey of 40,000 subjects. Aliment Pharmacol Ther. 2003;17:643-650.

3. Gulewitsch MD, Enck P, Hautzinger M, Schlarb AA. Irritable bowel syndrome symptoms among German students: prevalence, characteristics, and associations to somatic complaints, sleep, quality of life, and childhood abdominal pain. Eur J Gastroenterol Hepatol. 2011;23: 311-316.

4. Brun-Strang C, Dapoigny M, Lafuma A, Wainsten JP, Fagnani F. Irritable bowel syndrome in France: quality of life, medical management, and costs: the Encoli study. Eur J Gastroenterol Hepatol. 2007;19:1097-1103.

5. Akehurst RL, Brazier JE, Mathers N, et al. Health-related quality of life and cost impact of irritable bowel syndrome in a UK primary care setting. Pharmacoeconomics. 2002;20:455-462.

6. Maxion-Bergemann S, Thielecke F, Abel F, Bergemann R. Costs of irritable bowel syndrome in the UK and US. Pharmacoeconomics. 2006; 24:21-37.

7. Balboa A, Mearin F, Badía X, et al; RITMO Group. Impact of upper digestive symptoms in patients with irritable bowel syndrome. Eur $J$ Gastroenterol Hepatol. 2006;18:1271-1277.

8. Eriksson EM, Andrén KI, Eriksson HT, Kurlberg GK. Irritable bowel syndrome subtypes differ in body awareness, psychological symptoms and biochemical stress markers. World J Gastroenterol. 2008;14: 4889-4896.

9. Mönnikes H. Quality of life in patients with irritable bowel syndrome. J Clin Gastroenterol. 2011;45 Suppl:S98-S101. 
10. Charlson ME, Pompei P, Ales KL, MacKenzie CR. A new method of classifying prognostic comorbidity in longitudinal studies: development and validation. J Chronic Dis. 1987;40:373-383.

11. Ware JE, Kosinski M, Turner-Bowker DM, Gandek B. How to Score Version 2 of the SF-12 Health Survey (with a supplement documenting version 1). Lincoln, RI: QualityMetric Incorporated; 2002.

12. Hays RD, Morales LS. The RAND-36 measure of health-related quality of life. Ann Med. 2001;33:350-357.

13. Walters SJ, Brazier JE. What is the relationship between the minimally important difference and health state utility values? The case of the SF-6D. Health Qual Life Outcomes. 2003;1:4.

14. Samsa G, Edelman D, Rothman ML, Williams GR, Lipscomb J, Matchar D. Determining clinically important differences in health status measures: a general approach with illustration to the Health Utilities Index Mark II. Pharmacoeconomics. 1999;15:141-155.

15. Reilly MC, Zbrozek AS, Dukes EM. The validity and reproducibility of a work productivity and activity impairment instrument. Pharmacoeconomics. 1993;4:353-365.

16. DiBonaventura MD, Sun SX, Bolge SC, Wagner JS, Mody R. Health-related quality of life, work productivity and health care resource use associated with constipation predominant irritable bowel syndrome. Curr Med Res Opin. 2011;27:2213-2222.
17. Naliboff BD, Kim SE, Bolus R, Bernstein CN, Mayer EA, Chang L. Gastrointestinal and psychological mediators of health-related quality of life in IBS and IBD: a structural equation modeling analysis. Am J Gastroenterol. 2012;107:451-459.

18. Moisan C, Eschwege E, Basdevant A, Charles M, DiBonaventura M, Bonnelye $\mathrm{G}$. The epidemiology and burden of obesity and diabetes in France: a methodological comparison. Presented at the European Internal Society of Pharmacoeconomics and Outcomes Research Conference, Madrid, Spain, November 5-8, 2011.

19. Marrett E, DiBonaventura M, Zhang Q. Burden of illness associated with peripheral arterial disease in Europe. Presented at the European Internal Society of Pharmacoeconomics and Outcomes Research Conference, Madrid, Spain, November 5-8, 2011.

20. Bardin T, Khanna D, Perez-Ruiz F, et al. Quality of life, work impairment, and resource utilization associated with gout and its comorbidities across 5 EU countries: Results from the European National Health and Wellness Survey. Presented at the European League Against Rheumatism Conference, London, UK, May 25-28, 2011.

21. Kleinman L, Rentz A, Ciesla G, Kim JJ, Zacker C. Health-related quality of life associated with irritable bowel syndrome: comparison with other chronic diseases. Clin Ther. 2002;24:675-689.
Clinical and Experimental Gastroenterology

\section{Publish your work in this journal}

Clinical and Experimental Gastroenterology is an international, peerreviewed, open access journal, publishing all aspects of gastroenterology in the clinic and laboratory, including: Pathology, pathophysiology of gastrointestinal disease; Investigation and treatment of gastointestinal disease; Pharmacology of drugs used in the alimentary tract;

\section{Dovepress}

Immunology/genetics/genomics related to gastrointestinal disease. This journal is indexed on CAS. The manuscript management system is completely online and includes a very quick and fair peer-review system. Visit http://www.dovepress.com/testimonials.php to read real quotes from published authors. 